\title{
SOCIOLOGÍA DEL DERECHO VERSUS ANÁLISIS SOCIOLÓGICO DEL DERECHO
}

\section{Introducción}

El contenido del presente artículo no sólo pretende contribuir al debate abierto en los últimos años entre algún grupo de universitarios e intelectuales españoles sensibles a eso que, genéricamente, llamamos Sociología del Derecho o Sociología Jurídica, sino que -y principalmente- pretende rendir un personal homenaje y reconocimiento al profesor Elías Díaz. El porqué elegir este tema, y no el que constituye el objeto central del presente número monográfico, requiere una doble explicación. En primer, y principal, lugar, al rendir homenaje al profesor Elías Díaz con el desarrollo de este artículo, quisiera evidenciar y reconocer la labor que -desde hace ya más de dos décadas ${ }^{1}$ - ha realizado en favor de la consolidación científica, así como de la institucionalización académica, de la Sociología del Derecho en nuestro país.

La segunda razón es la de sumarme al debate antes aludido en torno a la fundamentación de los estudios socio-jurídicos y a su definitiva institucionalización en la Universidad española.

Al hilo de esta última explicación, debo hacer una pequeña alusión al título de este trabajo. En primer lugar, utilizo aquí la preposición latina «versus» no en su acepción más común y «cinematográfica» (léase «contra»), sino con el significado que en latín tenía dicha preposición, a saber: «hacia», esto es, «encontrarse frente a algo, pero en dirección hacia». Lo que intento poner de manifiesto con el título -y a continuación desarrollaré- es que la Sociología del Derecho, tal y como se ha fundamentado y desenvuelto, especialmente, en Europa, marcada por la eterna confrontación con la

\footnotetext{
${ }^{1}$ Recuérdese, que la primera edición de su Sociología y Filosofía del Derecho data de 1971.
} 
Dogmática Jurídica y, consecuentemente, por su difícil relación e incardinación con la Ciencia Jurídica, por las irreconciliables posturas de los sociólogos y los juristas, y marcada, en fin, por una metodología positivista, cuantitativa y descriptivista, entró en crisis $^{2}$, apenas comenzó su definitiva institucionalización académica en la década de los años setenta en toda Europa, salvo -como es sabido- en España. Incluso, la propia terminología de «Sociología del Derecho» o «Sociología Jurídica» suena hoy día un tanto anticuada. Por otra parte, los propios movimientos críticos del Derecho han dirigido sus críticas hacia la Sociología del Derecho tradicional, que se había realizado hasta las décadas de los años setenta y ochenta, por ser excesivamente formalista y legitimadora del orden establecido, demasiado avalorativa, demasiado acrítica y demasiado descriptiva ${ }^{3}$.

Finalmente, se ha producido, también, en las últimas décadas un significativo cambio de paradigmas en la Sociología del Derecho, así como la aparición o recuperación, en algunos casos, de otras metodologías o, incluso, la consolidación de un pluralismo metodológico en los estudios socio-jurídicos.

Todo lo apuntado conlleva -a mi juicio- la necesidad de buscar una nueva forma de entender y fundamentar los estudios e investigaciones socio-jurídicas o, incluso, una especie de Sociología del Derecho renovada, que debería «dirigirse hacia» (versus) el Análisis Sociológico de los Sistemas Jurídicos, entendido como un proyecto científico interdisciplinar y constructivista.

\section{Una breve referencia histórica a la sociología del derecho}

La Sociología del Derecho nació marcada por su confrontación con la Ciencia Jurídica, y como reacción al formalismo, dogmatismo

\footnotetext{
${ }^{2}$ A la referida crisis de la Sociología del Derecho subyace una crisis más profunda, que podría resumirse en la crisis epistemológica de la Sociología positivista. Al respecto, véase: C. Wright Mills, La imaginación sociológica, trad. cast. de F. M. Torner, F. C. E., 1993; A. Giddens, Las consecuencias de la modernidad, trad. cast. de A. Lizón, Madrid, Alianza Ed., 1993; E. Lamo de Espinosa, La sociedad reflexiva. Sujeto y objeto del conocimiento sociológico, Madrid, C.I.S., 1990; A. Touraine, Crítica a la modernidad, trad. cast. de M. Armiño, Madrid, Temas de Hoy, 1993; y P. Bourdieu, J. C. Chamboredon y J. C. Passseron, El oficio de sociólogo, trad. cast. de F. H. Azcurra, Madrid, Siglo Veintiuno, 1994.

${ }^{3}$ Desde una perspectiva más amplia, Boaventura de Sousa Santos, ha denunciado cómo la actitud de los sociólogos, tradicionalmente, «ha oscilado entre la distancia crítica con relación al poder instituido y el comportamiento orgánico con él, entre guiarlo y servirlo». Sin embargo -prosigue el autor-, «los desafíos que tenemos enfrente nos exigen salir de este péndulo. Ni guiar, ni servir. En lugar de distancia crítica, la proximidad crítica. En vez de compromiso orgánico, la libre involucra
} 
y legalismo, que eran las características dominantes de esta última a principios del siglo XX. En concreto, en la tradición de la cultura jurídica europea, la Sociología del Derecho se manifiesta principalmente a través de los movimientos sociologistas y antiformalistas, desarrollados dentro del propio pensamiento jurídico a principios del siglo $\mathrm{XX}$, los cuales supusieron una reivindicación de la perspectiva socio-cultural y socio-histórica del Derecho, así como una reivindicación de mayor flexibilidad en los mecanismos de funcionamiento interno de los sistemas jurídicos. Desde la Jurisprudencia de Intereses -que aportó la idea de fin $\mathrm{y}$, sobre todo, las ideas de interés y de conflicto, como elementos básicos de toda construcción científica del Derecho- ${ }^{4}$, pasando por el Movimiento Del Derecho Libre -que defendió una concepción pluralista del Derecho y de sus fuentes de producción, así como una concepción sociológica de la Ciencia del Derecho y un rechazo a los dogmas de la lógica deductiva y de la plenitud del ordenamiento jurídico ${ }^{5}$, hasta las denominadas corrientes realistas -que pretendieron elaborar una teoría sociologista del Derecho, partiendo de una redefinición de todas las categorías jurídico-ficticias elaboradas por la Dogmática ${ }^{6}$ se produjo toda una

ción. En lugar de serenidad autocomplaciente, la capacidad de espanto y de revuelta»: B. de Sousa Santos, Cinco desafios a la Imaginación Sociológica, en «No hay derecho», n. ${ }^{\circ}$ 8, 1992, pág. 31.

${ }^{4}$ Estas ideas fueron aportadas por Rudolf von Jhering, en la que se ha denominado segunda etapa de su pensamiento, marcada por un cierto talante sociologista del derecho, que se puede observar en tres de sus obras mas importantes: Der Zweck im Recht, Hildesheim-New York, Georg Olms Verlag, 1970, 2 vols.; existe traducción castellana a cargo de D. Abad de Santillán, México, Ed Cajica, 1961-62; Der Kampf ums Recht, 1872, existe traducción castellana a cargo de A. Posada, con un excelente prólogo de L. Alas, «Clarín», Madrid, 1891 (reimprimido en 1985 por la Ed. Civitas con una presentación de L. Díez Picazo): y, finalmente, una obra donde Jhering perfila una clarísima -y burlona- crítica contra la Jurisprudencia Dogmática y contra la Jurisprudencia Conceptual, titulada Scherz und Ernst in der Jurisprudenz, 1884, 9. ${ }^{\text {a }}$ ed., Leipzig 1904, existe traducción castellana a cargo de T. A. Banzhaf, bajo el título Bromas y veras en la Jurisprudencia, Buenos Aires, 1974.

${ }^{5}$ Los autores más conocidos del referido movimiento son Eugen Ehrlich y Hermann Kantorowicz. La casi totalidad de las obras y artículos publicados por Ehrlich se encuentran en la actualidad recopilados por M. Rehbinder en dos volúmenes titulados: Rechts und Lebe. Gesammelte Schriften zur Rechtstatsachenforschung und zur Freirechtslehre von Eugen Ehrlich, Berlin, 1967; y, Gesetz und lebendes Recht, Berlín, 1986. Respecto a la obras de Kantorowicz, éstas se encuentran recopiladas por Thomas Würtenberger, Rechtwissenschaft und Soziologie, Karlsruhe, Verlag C. F. Müller, 1962.

${ }^{6}$ Dentro de las corrientes realistas, y en concreto en el ámbito cultural europeo, podemos destacar el Realismo Jurídico Escandinavo, con Alf Ross como figura más representativa, con su obra titulada On Law and Justice, Stevens and Sons Limited, London, 1958; existe traducción castellana a cargo de G. R. Carrió, en Eudeba. Buenos Aires, 1977. 
corriente crítica frente a las construcciones científicas del derecho realizadas por los juristas, que tuvieron como fruto la introducción -y posterior consolidación académica- de una perspectiva de análisis del Derecho novedosa hasta ese momento, cual era la perspectiva sociológica del Derecho o Sociología Jurídica.

Posteriormente, la institucionalización y desarrollo de la Sociología del Derecho, como disciplina académica, se realizó, casi siempre, en el seno de los Departamentos de Teoría y Filosofía del Derecho, lo cual condicionó notablemente la forma en que se ha ido desarrollando el contenido de dicha disciplina. En efecto, los sociólogos del derecho en Europa -con la excepción de los países escandinavos, que han estado notablemente influenciados por la cultura anglosajona- han prestado más atención a la dimensión epistemológica, metodológica, histórica, teórica y sistemática de la Sociología del Derecho, en detrimento de la perspectiva empírica de la misma, obstaculizando, a su vez, el desarrollo de sociologías jurídicas particulares. Esto dio lugar a que, en el ámbito de la doctrina centroeuropea, la Sociología del Derecho hasta la década de los años setenta se haya visto reducida, o bien a un mero sociologismo jurídico, o bien a una mera teoría sociológica del derecho. Esto se produjo así, porque el traspasar los límites de una Sociología del Derecho teórica, histórica y metodológica implicaba forzar en extremo la coherencia teórica de los profesionales de las disciplinas filosófico-jurídicas, dado que el método de análisis empírico, propio de la Sociología del Derecho, es radicalmente diferente del propio de la materia filosófico-jurídica. Especialmente, si tenemos en cuenta cuáles eran los fundamentos epistemológicos dominantes en las ciencias sociales hasta la década de los años setenta, a saber: la metodología descriptivo-positivista, que propugnaba una Sociología del Derecho avalorativa, apolítica, acrítica y descriptivista, lo cual resultaba bastante incompatible con la labor esencial del filósofo del Derecho, que consistía, fundamentalmente, en valorar y criticar no en describir acríticamente.

Esta vinculación de la Sociología del Derecho con la Filosofía del Derecho ha tenido todavía dos consecuencias, que han condicionado el desarrollo posterior de aquélla.

La primera afecta a la relación de los juristas con la Sociología del Derecho o, si se quiere, a la relación de ésta con la Ciencia Jurídica. La Sociología del Derecho ha corrido la misma suerte que la Filosofía del Derecho en relación con lo que podemos denominar «juristas» en sentido estricto. Al igual que el filósofo del Derecho, durante décadas, se ha visto obligado a justificar su labor y su disciplina en los propios planes de estudio de la Licenciatura en Derecho, también el sociólogo del Derecho se ha visto, y se ve hoy día todavía 
en algunos países ${ }^{7}$, obligado a justificar día a día la importancia y la necesidad de su actividad, tanto para la formación académica de los juristas, como para el mejor funcionamiento del propio sistema jurídico, frente a la oposición radical de los propios juristas. La propia historia de las relaciones entre Ciencia Jurídica y Sociología del Derecho es bastante significativa. Esta última se abrió paso no tanto justificando su propia identidad científica, como criticando los errores y los reduccionismos en que la Ciencia Jurídica había incurrido, y a veces, incluso, desvalorizando científicamente a la misma Ciencia Jurídica. Los juristas dogmáticos, por su parte, siempre han considerado a la Sociología del Derecho como una disciplina menor e instrumental, sometida a la Ciencia Jurídica (Kelsen) o, en el mejor de los casos, como algo de «sociólogos», lo cual proviniendo de ellos tenía una clara connotación peyorativa.

Por otra parte, el hecho de que tradicionalmente se ha fundamentado la autonomía científica de la Sociología del Derecho en un aspecto metodológicamente externo, ha favorecido el desarrollo de una especie de «Sociología del Derecho de los sociólogos»o -como la ha denominado Febbrajo- una «sociología de las instituciones Jurídicas» o de la «eficacia» del Derecho ${ }^{8}$, más ocupada en estudiar la eficacia de las normas y de las instituciones jurídicas, los comportamientos de los destinatarios de aquéllas, las organizaciones sociales o, en pocas palabras, los «hechos del Derecho», que de afrontar desde dentro los problemas estructurales y de funcionamiento interno de los propios sistemas jurídicos, en conexión también con sus contextos culturales, políticos y económicos. Esta toma de postura inicial dio lugar a que se considerara que la Sociología del Derecho era una parte de la Sociología general, que estudiaba el Derecho desde fuera ${ }^{9}$, mientras que la Ciencia jurídica lo estudia desde una perspectiva interna, con lo cual se produjo, cada vez más, una separación e, incluso, incomunicación entre la Sociología del Derecho y la

${ }^{7}$ El ejemplo español, con respecto a la reciente elaboración de los nuevos Planes de Estudio, es paradigmático.

${ }^{8}$ A. Febbrajo, Sistemas Sociológicos y Teoría Jurídica. Algunos dilemas de una Sociología del Derecho «crítica», en R. Bergalli (Coord), El Derecho y sus realidades, Barcelona, P. P. U., págs. 71-100; más ampliamente desarrolla todas estas ideas en, Per una sociologia del diritto "critica», en Uberto Scarpelli y Vincenzo Tomeo (Eds.) Societá, norme e valori. Studi in onore di Renato Treves, Milano, Giuffré, 1984, págs. 227-258; aquí el autor habla de la «Sociología sin Derecho».

${ }^{9}$ En este sentido se manifestó Jean Carbonnier, Sociologie Juridique, París, Librairie Armand Colin, 1972; se cita aquí la traducción castellana de L. Díez-Picazo, Sociología Jurídica, Madrid, Tecnos, 1977, pág. 17. En España, una postura similar fue defendida por Elías Díaz, Sociología y Filosofía del Derecho, Madrid, 1991; y por L. García San Miguel, Notas para una crítica de la razón jurídica, Universidad Complutense, Madrid, 1985, págs. 63-120. 
Ciencia Jurídica, como perspectivas científicas paralelas -que nunca encontraban un punto de unión-, que estudiaban el mismo objeto desde puntos de vista diferentes.

Una Sociología del Derecho, así entendida, incurría en un reduccionismo fáctico, olvidando que los denominados «hechos del Derecho» no se nos presentan de antemano, en forma bruta, en la realidad empírica, sino que son «construidos» mediante un proceso de interacciones entre objeto de conocimiento y sujeto cognoscente, y olvidando, también, que el carácter esencialmente «jurídico» de esa denominada «facticidad» del Derecho no puede ser ignorado o entendido exclusivamente en términos de acción social o de organización social.

La segunda consecuencia antes aludida -y estrechamente relacionada con la anteriorse refiere a la, hasta ahora, «irreconciliable» postura de los juristas y de los sociólogos en torno a cómo ha de entenderse y desarrollarse la Sociología del Derecho. Ambas posturas están enmarcadas en una serie de dogmas o mitos, que, de ahora en adelante, debemos desenmascarar:

- La tensión entre la perspectiva «interna» y la perspectiva «externa», esto es, la tensión entre una Sociología del Derecho de los juristas y una Sociología del Derecho de los sociólogos.

- La autodefinición del sociólogo del derecho como observador acrítico y objetivo, que describe solamente «hechos» del Derecho.

- El dogma de la radical separación entre el ámbito del «ser»y el ámbito del «deber ser», con la consiguiente crítica realizada por los juristas a los sociólogos de dedicarse solamente al estudio del «ser», esto es, de la «facticidad», o en el mejor de los casos, de mezclar ambos ámbitos de conocimiento, transgrediendo, así, otro de los dogmas tradicionalmente defendido por los juristas dogmáticos, cual es: la imposibilidad de pasar legítimamente de un ámbito al otro, sin romper la coherencia $\operatorname{cognoscitiva}^{10}$.

- El empeño -a veces infructuoso- de delimitar y definir el objeto de conocimiento de la Sociología del Derecho. A lo largo de los años, los juristas y los sociólogos no se han puesto de acuerdo en esta materia: o bien, se le ha negado a la Sociología

${ }^{10} \mathrm{Cfr}$. al respecto la propuesta de superación del dogma de la separación entre el mundo del «ser» y el del «deber ser», dada por André-Jean Arnaud, El concepto de «razón jurídica» como modelo de superación de la oposición tradicional entre el ser y el deber ser, en El derecho sin máscara, San Sebastián. Laboratorio de Sociología Jurídica, 1990, págs. 167-183. Más ampliamente, también en: Où va la sociologie du droit?, París, L. G. D. J., págs. 346 y ss. 
del Derecho la posibilidad de formalizar su objeto de conocimiento $y$, consecuentemente, se ha predicado su dependencia y su carácter auxiliar con relación a la Ciencia Jurídica (postura kelseniana); o bien se ha delimitado el objeto de conocimiento de la Sociología del Derecho en términos de acción social o de comportamientos (posturas sociologistas) y, en definitiva, en términos antinormativistas.

Quizá haya llegado el momento de desmitificar estos dogmas: de compaginar la perspectiva interna y la perspectiva externa de la Sociología del Derecho, desde una perspectiva interdisciplinar y crítica; de transgredir los lindes respectivos del ámbito del «ser» y del ámbito del «deber ser», lo cual implicaría transgredir, también, los postulados epistemológicos del positivismo descriptivista y dar cabida a las dimensiones políticas, económicas y valorativas del Derecho; y, por último, quizá haya llegado el momento de no perdernos indefinidamente en el debate sobre la formalización del objeto de conocimiento de la Sociología del Derecho, y de admitir que ésta no tiene, en realidad, un objeto de conocimiento propio y autónomo, sino que la Sociología del Derecho estudia el Derecho en su totalidad y en sus interacciones con diferentes factores sociales (política, cultura, economía, etc...). Lo que debe unir a los diferentes investigadores, con formaciones académicas diversas (juristas, economistas, sociólogos, antropólogos...), que se acercan al análisis del Derecho desde la óptica sociológica, es el interés por contribuir a un proyecto científico interdisciplinar, donde tengan cabida, también, los aspectos económicos, políticos y valorativos, más allá de las iniciales posturas «sociologistas» o «realistas» de la Sociología del Derecho tradicional ${ }^{11}$.

\section{El análisis sociológico de los sistemas jurídicos como proyecto interdisciplinar}

Comenzaba este artículo diciendo que el término Sociología del Derecho tiene una cierta connotación anticuada, y que prefería hablar de Análisis Sociológico de los Sistemas Jurídicos. El cambio de terminología no es un capricho, ni refleja simplemente una preferencia semántica, sino que tiene tras de sí otros cambios, que -a mi

${ }^{11}$ Cfr. François Ost, Dogmatique juridique et science interdisciplinaire du droit, en «Rechtstheorie», n. ${ }^{\circ}$ 17/1986, págs. 86-110; y André-Jean Arnaud, Droit et Société: du constat a la construction d'un champ comun, en «Droit et Société»10/21, 1992, págs. 17-37. 
juicio- han influido en la forma de enfocar y entender actualmente los estudios e investigaciones socio-jurídicas. Veamos a continuación algunos de ellos ${ }^{12}$ :

En primer lugar, es inevitable hablar de un cambio metodológico en las ciencias sociales, que ha afectado también a la Sociología del Derecho ${ }^{13}$. En las últimas décadas hemos asistido a una fuerte crisis de la metodología positivista en todos los ámbitos (filosófico, científico, jurídico), y también en el ámbito sociológico. Los principios del descriptivismo, del determinismo, del cientificismo, de la radical separación entre sujeto cognoscente y objeto de conocimiento, de la incomunicación entre el mundo del «deber ser» y el mundo del «ser», han sido puestos en tela de juicio en las dos últimas décadas ${ }^{14}$. Frente a esta lógica positivista se ha producido un regreso a otras teorías epistemológicas, tales como el interaccionismo simbólico, la fenomenología, la epistemología constructivista, la epistemología comprensiva, los métodos sociológicos de análisis de sistemas $\mathrm{y}$, consecuentemente, se ha producido también un auge e interés por los aspectos microsociológicos en detrimento de los macrosociológicos; todo lo cual ha permitido dar sentido interpretativo a los meros datos del análisis empírico-cuantitativo. Desde este pluralismo metodológico, imperante en la actualidad en las ciencias sociales, el Análisis Sociológico de los Sistemas Jurídicos debe partir de la consideración de que el Derecho no es un objeto de conocimiento dado de antemano, a priori, que se observa externamente y se describe, sino que debe ser construido en base a diferentes intereses cognoscitivos, donde el investigador es parte también de lo que investiga ${ }^{15}$.

En segundo lugar -y junto al referido cambio metodológico- se ha producido también, en las dos últimas décadas, un cambio de paradigmas que afectan directamente a los estudios socio-jurídicos ${ }^{16}$.

${ }^{12}$ Cfr. Rita J. Simon y James P. Lynch, The Sociology of Law: Where we have been and where we might be going, en «Law and Society Review», n. ${ }^{\circ} 235$, 1989, págs. 825-846.

${ }^{13} \mathrm{Cfr}$. al respecto la bibliografía citada en supra nota $\mathrm{n} .^{\circ} 2$; y, también, Jacques Commaille y Marie-Pierre Marmier-Champenois, Los métodos de la Sociología Jurídica en relación con los métodos de la Sociología General, en «Revista del Ilustre Colegio de Abogados del Señorío de Vizcaya», n. ${ }^{\circ} 24,1985$.

${ }^{14}$ Cfr. al respecto, María José Fariñas Dulce, Filosofía del Derecho «versus» Teoría del Derecho», en «Anuario de Filosofía del Derecho», Madrid, 1992, págs. 207-222, y la bibliografía allí citada.

${ }^{15} \mathrm{Cfr}$. al respecto las opiniones de A. J. Arnaud, Du jeu fini au jeu ouvert. Réflexions additionnelles sur le Droit post-moderne, en «Droit et Société», n. ${ }^{\circ}$ 1718, 1991, págs. 38-55; y Boaventura de Sousa Santos, Droit: une carte de lecture déformée. Pour une conception post-moderne du droit, en «Droit et Société», n. ${ }^{\circ}$ 10, 1998, págs. 363-390.

${ }^{16}$ Crf. David Nelken, Changing Paradigms in the Sociology of Law, Gunther 
Por ejemplo, emerge cada vez con más fuerza la vieja idea del pluralismo, tanto social, como cultural y jurídico y, consecuentemente, el rechazo a que todo lo «jurídico» se identifique con el derecho estatal, al menos desde un punto de vista práctico. Va tomando auge la idea, según la cual coexisten una pluralidad de sistemas jurídicos (o formas alternativas de normatividad) a veces armónicamente y otras no; y, por tanto, la ecuación «todo los jurídico es igual a derecho estatal» se pone en tela de juicio, desde diferentes sectores. Pero la idea del pluralismo va más allá: en la actualidad se habla cada vez con mas fuerza del pluralismo en las fuentes del derecho, lo cual se traduce en una mayor participación de la «sociedad civil» en la producción normativa; así como de un pluralismo en los medios, a veces formales, otras informales o alternativos (por ejemplo los «street committees») de resolución de conflictos, dando lugar a lo que ya se denomina un pluralismo judicial.

Otra idea, hoy significativa en el ámbito de los estudios socio-jurídicos, es la de la indeterminación, que, por otra parte, ha sido uno de los elementos filosóficos más defendidos por el movimiento conocido como Critical Legal Studies, desarrollado a partir de la década de los años setenta en los Estados Unidos ${ }^{17}$. Según esta tesis, todas las decisiones jurídicas (las legales, las judiciales e, incluso, las constitucionales) están marcadas por la característica de la indeterminación ${ }^{18}$, que no arbitrariedad. Esto quiere decir, que

Teubner, Autopoietic Law: A New Approach to Law and Society, Berlín, De Gruyter, 1988.

${ }^{17}$ Sobre la reciente historia de este movimiento, véase: Duncan Kennedy, Nota sobre la historia de los CLS en los Estados Unidos, en «Doxa», n. 11, 1992, págs. 283-293; Agostino Carrino, Solidaridad y Derecho. La Sociología Jurídica de los "Critical Legal Studies», en «Doxa», n. ${ }^{\circ}$ 12, 1992, págs. 115-153 (y bibliografia allí citada); R. Unger, The Critical Legal Studies Movement, Harvard University Press, 2. ${ }^{a}$ ed. 1986; Boyle (ed.) Critical Legal Studies, Hampshire, 1992; Richard Abel, Voz: Critical Legal Studies, en Dictionnaire Encyclopédique de Theorie et de Sociologie du Droit, 2. ${ }^{a}$ ed., París, L. G. D. J.-E. J. A., 1993; y sobre la recepción en España de este movimiento, véase: Albert Calsamiglia, La retórica de Critical Legal Studies. Impresiones de un lector español, en «Doxa», n. ${ }^{\circ} 11,1992$, págs. 295-3 10.

${ }^{18}$ Sobre esta tesis de la indeterminación, como elemento filosófico-jurídico de los Critical Legal Studies, véase el ensayo de Joseph Singer, The Player and the Cards: Nihilism and Legal Theory, en «Yale Law Journal», vol. 94, 1984, págs. 1-76, donde llega a afirmar que no sólo el material legal y el conjunto de técnicas de razonamiento jurídico son indeterminadas, sino también las teorías jurídicas, que se elaboran para justificar el propio sistema jurídico, ya que «esas mismas teorías podrían ser utilizadas para justificar cosas diferentes» (pág. 24).

Por otra parte, la defensa extrema de esta tesis ha llevado a gran parte de los autores pertenecientes al referido movimiento a caer en un nihilismo y en un escepticismo filosóficos contradictorios con su pretendida ideología política de izquierdas. Cfr. al respecto las observaciones críticas de Albert Calsamiglia, La retórica de Critical Legal Studies. Impresiones de un lector español, op. cit. 
el conjunto del sistema jurídico (con todo su material legislativo y sus técnicas de razonamiento jurídico) no siempre tiene una respuesta específica para cada problema o cuestión jurídica planteada, en contra de lo que las tesis del formalismo jurídico habían venido sosteniendo; sino que, incluso, con el mismo material jurídico se puede llegar a soluciones diferentes y, aún a veces, contrarias $^{19}$. Esto plantea, a su vez, la necesidad de reconocer la existencia de lo que se ha denominado espacios de «no derecho» en las decisiones jurídicas, lo cual es especialmente sensible al análisis sociológico.

Por otra parte, en el ámbito de los estudios socio-jurídicos se ha producido, en los últimos años, una apertura hacia la política y la economía, principalmente. Es ésta, también, una aportación de los movimientos «críticos» del Derecho, ya que éstos consideraban que, tanto la Teoría Jurídica como la Sociología del Derecho tradicionales, se movían en unos parámetros excesivamente formalistas y descriptivistas. De esta forma, la Sociología del Derecho tradicional tan sólo aportaba una reivindicación realista o sociologista de aproximación al Derecho, pero manteniendo el mismo presupuesto descriptivista y acrítico de la Teoría Jurídica. Frente a esto, los desarrollos actuales del Análisis Sociológico de los Sistemas Jurídicos toman en consideración también la dimensión política y la económica del Derecho, así como la valorativa. Desde un punto de vista cognoscitivo y explicativo de las interrelaciones entre Derecho y Sociedad, aquél no puede ser aislado de sus propios contextos socio-políticos y socio-económicos e, incluso, socio-antropológicos, ya que todos ellos forman parte de la dimensión sociológica del Derecho ${ }^{20}$.

Todo esto nos lleva, por fin, a la característica -a mi juicio- mas determinante del actual Análisis Sociológico de los Sistemas Jurídicos, cual es la interdisciplinariedad. El desarrollo actual de los estudios socio-jurídicos está marcado, no sólo por la inevitable colaboración y el inevitable entendimiento entre juristas y sociólogos -cosa que la Sociología del Derecho tradicional no consiguió-, sino entre juristas y otros investigadores de formaciones académicas diversas (economistas, politólogos, criminólogos, asistentes sociales, antropólogos, psicólogos...). Se trata de que especialistas de disciplinas científicas y académicas diversas trabajen conjuntamente por un

${ }^{19}$ Esta tesis de la indeterminación tuvo una especial aplicación, por parte de los Critical Legal Studies, en el ámbito del Derecho Constitucional, habida cuenta del carácter político que tiene la Corte Suprema en los Estados Unidos. Cfr. al respecto, Mark Tushnet, Critical Legal Studies y Derecho Constitucional, en «No hay Derecho», año IV, n. ${ }^{\circ} 9.1993$, págs. 32-33.

${ }^{20}$ Cfr. Franz von Benda-Beckmann, Unterwerfung oder Distanz: Rechtssoziologie, Rechtsanthropologie und Rechtspluralismus aus rechtsanthropologischer Sicht, en «Zeitschrift für Rechtssoziologie», n. ${ }^{\circ}$ 1/1991, pág. 96-119. 
proyecto científico común, cual es: el estudio e investigación empírica de las relaciones entre Derecho y Sociedad, en su sentido más amplio. Evidentemente, este planteamiento tiene una premisa importante, que consiste en superar las viejas controversias entre juristas y sociólogos en torno a cuál debe ser el objeto de conocimiento de la Sociología del Derecho, puesto que ya hemos visto cómo a lo largo de los años ni unos ni otros han conseguido llegar a un punto de acuerdo. Nada merma el interés científico ni la legitimidad de las investigaciones socio-jurídicas, el reconocer que esta Sociología del Derecho «renovada», que proponemos, no tiene un objeto de conocimiento propio e independiente, incluso ni siquiera tiene una metodología propia e independiente. El actual Análisis Sociológico de los Sistemas Jurídicos ni se ocupa sólo de comportamientos u organizaciones sociales, ni sólo de instituciones jurídicas y operadores jurídicos, sino de todo lo que forma parte del sistema jurídico en su totalidad, considerado en relación con su contexto sociológico. Se trata de contribuir, por tanto, a la realización de ese proyecto científico común, consistente en las investigaciones y estudios socio-empíricos de los sistemas jurídicos, desde un punto de vista constructivista.

Por último, el actual Análisis Sociológico de los Sistemas Jurídicos, con las características hasta ahora señaladas, debería -a mi juicio- constituirse como un análisis permanentemente crítico del funcionamiento interno de los sistemas jurídicos, que contribuya a conseguir una cada vez más armónica relación entre las reglas y técnicas jurídicas y las exigencias de la totalidad de la sociedad. De esta manera, se recupera, junto a las ya tradicionales funciones cognoscitivas e instrumentales de la Sociología del Derecho, la función crítica de la misma, que fue propuesta y defendida por los movimientos críticos del Derecho, tanto en Europa (Escuela de Frankfurt y la corriente de la Kritische Rechtssoziologie) como en los Estados Unidos (Critical Legal Studies) desde la década de los años setenta. 
$\triangle$ 